\title{
A New Approach for Delivering e-Learning Complex Courses in Indonesia
}

\author{
Sumenge Tangkawarouw Godion Kaunang1,2, Tsuyoshi Usagawa ${ }^{2}$ \\ 1 University of Sam Ratulangi, Kampus Unsrat, Manado, Indonesia. \\ 2 Graduate School of Science \& Technology, Kumamoto University, Kumamoto, Japan. \\ *Corresponding author. Email: odikaunang@hicc.cs.kumamoto-u.ac.jp, odikaunang@yahoo.com \\ Manuscript submitted December 23, 2016; accepted April 1, 2017. \\ doi: 10.17706/ijeeee.2017.7.2.132-145
}

\begin{abstract}
Efficacy of delivery methods can be compared by studying human memory emphasizing how information is processed. The aim of this research is to identify factors which are influenced by methods of complex e-learning course delivery. Compilation of cognitive load theory and learning ability of Moodle survey plugin aids in analyzing evidence. Two plug-ins - browser extensions which, in this case, were used to monitor user usage - called COLLES (constructivist on-line learning environment survey) and ATTLS (attitudes toward thinking learning survey) were instrumental in measuring user perceptions. Both surveys aided stakeholders (students, instructors, and system managers) in measuring human interaction in order to identify optimal methods. Results suggest that interactivity and connected-knowing approaches are factors that influenced optimal design for complex e-learning course delivery in an Indonesia environment. Our research also opens possibilities towards future research on the influence of gender on learning.
\end{abstract}

Key words: E-learning, the complex e-learning course, method of delivering, Indonesia.

\section{Introduction}

\subsection{Background}

Personal and social interaction is by nature embedded in each human, while the human brain differs by individual. As such, interaction ability differs and is unique, and each interaction in the method of e-learning system must be specific for each human brain. The Massachusetts Institute of Technology (MIT) started publishing educational resources online as OpenCourseWare (OCW) in 2001, while Massive Open Online Course (MOOCs) initiatives were launched soon after; however, delivery methods have yet to consider students with various computer literacy levels in developing countries. Both MOOCs and OCW-MIT initiatives ignore student readiness as an obstacle of e-learning, instead simply conducting courses using a mass approach rather than using a specific-personal approach. Attention to methods on proper content delivery would better ensure delivery of educational targets. As such, a new method for delivering complex content e-learning course utilizing specific approaches tailored to specific purposes is necessary.

\subsection{Study Literature}

Publications which have discussed effectiveness of the e-learning field can be broadly classified into two types: personalized and collaborative. The personalized type relates to personal human ability such as a cognitive ability, motor skill, and behavior performance. The collaborative type relates to interaction between resources removed from human interaction such as educational technology, management systems, 
and community structures.

Numerous publications have dealt with personalized on e-learning activities. For example, in Limongelli C. et al. (2011) [1] "Personalized e-learning in Moodle: The Moodle_LS System," they observed and modeled learners to adapt their learning experiences accordingly using new technology and, more importantly, methodological perspective in e-learning. Jason Wright (2016) [2] in his column at AtTech Digest discussed how personalized learning not only improves a student's ability to return information but also increases a student's willingness to learn. Mateo Gaeta et al. (2015) [3], in their "An approach to personalized e-learning," stated that personalization can be exploited in e-learning system, focusing on their proposal, an intelligent web tracker.

Other papers concern interactivity as a part of social-mass collaborative aspects. Inma Rodriguez-Ardura et al. (2016) [4] empirically examined how the impact of interactivity elicited by an e-learning environment unleashes imagery that in turn facilitates special presence and copresence as well as flow. They found that significant paths are from interactivity to flow and from flow to e-learner response variables (attitude, intention to continue and actual continuance behavior). Erman Yukselturk et al. (2008) [5] introduce "Learning community formation through interaction, well structured and guided project or problem-based group activities, considering instructional design and cognitive principles in the design of the program and flexibility in time and selection of the course" that should be taken into account in designing online program. Stevy Domagk et al. (2010) [6] introduced a unifying model that includes the user, the learning environment, and a system of connection and concept that together make up interactivity. Such a model can help inform research, discussion, and design decisions on interactive multimedia instruction.

Although the publications above reported on the effectiveness and benefits of the personal and collaborative approach, none discussed specific ways for delivering a complex e-learning course. Complex e-learning course delivery means that intended for students with such barriers as those to computer literacy and internet connection. Instructors face many obstacles preparing compact e-learning courses such as lack of management to overcome copyright problems; the complexity of the learning aspect is how to run the e-learning system without reduce the content goals despite the many barriers, and how to maximize existing facilities. At the same time, innovation in educational technology changes rapidly, requiring adaption. Therefore, new methods for facilitating a complex e-learning must be identified and constantly updated, including how to optimize existing resources. Edmund Tovar and Nelson Piedra (2014\} [7] note that Open Educational Resources (OER) initiatives will enable teaching and teacher-student interaction that are the real core of teaching and learning, rather than on the continual creation of educational material.

The following publications relate specific modes on updating delivery methods. Andrea Ionescu (2012) [8] introduced a new learning method using databases corresponding with practical and theoretical necessities to report with end users, the learners. He purposed a solution to improve learning processes for virtual classes. Kusuma Ayu Laksitowening and Zainal A.Hasibuan (2015) [9] introduced a personalized e-learning architecture model. They explore various theories and best practices of e-learning and compare various ways of learning based on the cultural diversity of Indonesia.

Both Andrea [8] and Kusuma et al. [9] introduce new methods and models dedicated to specific environments. While each environment needs a specific approaching, the specific environment of educational components (student, teacher, and system) is under constant flux and must be adapted using state of the art educational technology to diversities of cultural and human life style. Luis Palacios and Chris Evans (2013) [10] wrote on guidelines for instructional designers to maximize students' learning by using appropriate types of interactivity related to specific activities. Furthermore, some types of interactivity produce the effect of increasing the learner's cognitive ability to remember information (memory effect), 
while other types of interactivity increase the learner's cognitive ability to understand the learning message (transfer effect). Adding interactivity of the two types magnify effects as they increase memory and deep learning. Moreover, Heath Marrs and Stephen L. Benton (2008) [11] wrote a paper "Relationships between separate and connected knowing and approaches to learning". They introduced ways of knowing and explored whether connected and separate ways of knowing were related to deep and achieving approaches to learning.

Content and method are coupled. Identification of a proper way for delivering e-learning complex course needs knowledge of human memory. Regarding the relation between e-learning and human-memory, Jeroean van Meirrenboer and Paul Ayres (2015) [12] wrote in their paper "Research on cognitive load theory and its design implications for e-learning" on the parts of human-memory and the role of each part in information processing. They identified three cognitive load functions - intrinsic, extraneous, and germane - and proposed a method to adapt these toward e-learning.

\subsection{Hypothesis}

Based on all the papers and a book on part 1.2, utilization of all human memory functions can enhance educational achievement. Interactivity will become significant on how to prove our hypothesis; in short, effectiveness of delivering method is to enhance interactivity.

\subsection{Objective}

Our objective is to identify factors influencing e-learning method effectiveness. The factors are influence the effectiveness will be reflected by COLLES and ATTLS. Specifically, we look to identify new ways to deliver complex e-learning courses using a sample of Indonesian students who study engineering.

\section{Methodology}

\subsection{Collect Data}

Data was collected in two ways, by survey and by extracting from log Moodle server. The survey was offered both offline and online. Data came from three e-learning class activities covering special topics offered by the electrical department instructor, Sam Ratulangi, regarding programming of electrical power systems during the second semester 2015 and the first semester 2016. Numeric method experiment covered the first semester 2016.

Sumenge Godion Kaunang et al. (2015) [13] reported on their experiment to implement a complex e-learning course. They conducted an e-learning class in which students and lecturer positions far removed. The lecturer uploaded contents and ran the learning process from Japan, while the students were in Indonesia. The meetings were divided into two parts separated by a mid-test. The theory was delivered in the first part, and experiments in the second. Each part consisted of several meetings. Student submitted their reports individually.

Sumenge Tangkawarouw Godion Kaunang et al. (2016) [14] showed student perceptions of a virtual programming lab when they conducted a complex e-learning course whose contents were the same as in 2015; however, experiments were delivered in the first part and theory in the second. Students conducted activities more in groups than alone. In the third class, students did experiments in groups.

\subsection{Survey: COLLES and ATTLS}

Constructivist On-Line Learning Environment Survey (COLLES) and Attitudes Toward Thinking Learning Survey are plug-in surveys using a Moodle platform [15]. The following papers respectively introduced what were the theory works on COLLES and ATTL.

Taylor.P and Maor D.(2000) [16] wrote six items to measure students' and tutors' perception of 
professional relevance, reflective thinking, interactivity, cognitive demand, affective support and interpretation of meaning. The COLLES regarded the existence e-learning classes that support all participants to reconstruct themselves as both reflective and collaborative learners.

Kathleen M.Galotti et al. (1999) [17]wrote a paper entitled "A new way of assessing way of knowing: The Attitudes Toward Thinking and Learning Survey (ATTLS)" in which they introduced instrumental ways of knowing, which are Connected Knowing (CK) and Separated Knowing (SK). The instruments, which were related to various measures of preference, showed acceptable internal reliability. Results indicate that "Connected Knowing" and "Separated Knowing" may function more as approaches or style than basic abilities.

As COLLES and ATTLS have been made a plug-in in Moodle, student perception can be recorded online. Both COLLES and ATTLS relate to humans individually; however, survey impact analysis is unable to discern how human memory acquires knowledge. The methodology of this research was analyses of correlation between theory of human memory and data from COLLES and ATTLS. Offline surveys focused student perceptions of content and tools.

Clare Power and Kiyoni Dunphy (2010) [18] used a qualitative approach in their published paper "Peer facilitated learning in mathematics for engineering: case study of an Australian University." We used the same qualitative approach on how data is produced because the study area of mathematics for engineers used in their paper share characteristics with our target group, with classes containing similar complexity of content. Our intended use of the COLLES and ATTLS explicated models was to determine how they operate in our particular - that is, Indonesian - context.

\subsection{Human Memory and Cognitive Learning}

COLLES and ATTLS contribute to the study of human perceptions; human perception is inseparable from human memory; and, therefore, the methodology is built to connect human memory and the e-learning process. In other words, understanding how human memory processes information will aid in adopting a method to ensure its most efficient and effective delivery.

Atkinson R.C. and Shiffrin R.M.(1968) [19] in their book wrote on the theory of human memory, describing structural components of the memory system and processes that control memory storage and retrieval. These control processes act upon and reside in three structural components: short-lived sensory memories, short-term store(s), and the relatively permanent long-term memory. The term "working memory" describes the control processes that primarily reside in the short-term component of the system.

Jeroean van Meirrenboer and Paul Ayres (2015) in reference [12] wrote that novel information must be processed in working memory in order to construct schemas, after which they may become automated if they are repeatedly and successfully applied. Working memory load may be affected by element interactivity of the learning tasks themselves (intrinsic cognitive load), the manner in which the tasks are presented (extraneous cognitive load), or the amount of cognitive resources that learners willingly invest in schema construction and automation (germane cognitive load). Cognitive load theory (CLT) has become useful for design of large courses and e-learning programs that are characterized by a high level of interactivity.

Both Atkinson R.C [19] and van Meirrenboer [12] portray human memory works which help identify optimal ways to design e-learning courses. E-learning efficacy may suffer due to misunderstanding of human memory theory. The methodology is divided into two steps: The first to collect data from three complex courses; the second to analyze data which are mutually influenceable and their relations. Subsequently, this data was compiled against the theory of human memory to create a list of significance from order of high to lower. 


\section{Result}

Twenty-nine students submit questionnaires of the special topic, programming on electrical power system course, 2016. Thirty-two students submit questionnaires regarding their experiments on numeric method course, 2016, while eleven students submitted questionnaires regarding their special topic of programming on electrical power systems in 2015. Results expected were how educational technology successfully supports e-learning complex courses - and particularly, identification of what e-learning tools encourage engagement in delivery methods. Dougiamas M. and Taylor P. on the reference [15] introduced interpretative analysis of an e-learning course constructed using Moodle survey plug-in, COLLES and ATTLS.

\subsection{COLLES and ATTLS at the Programming on Electrical Power System Class 2016}

The following figures shows of The Constructivist On-Line Learning Environment Survey (COLLES). The COLLES Moodle plug-in reported six items based on preferred and actual student perception: relevance, reflective thinking, interactivity, tutor support, peer support and interpretation. The items relate to the five Likert Scale options: almost never, seldom, sometimes, often, and almost always. These options are shown on the vertical axes. On the last figure, COLLES provides a conclusion figure related to the previous items. A gap appears when preferred conditions differ from actual conditions.

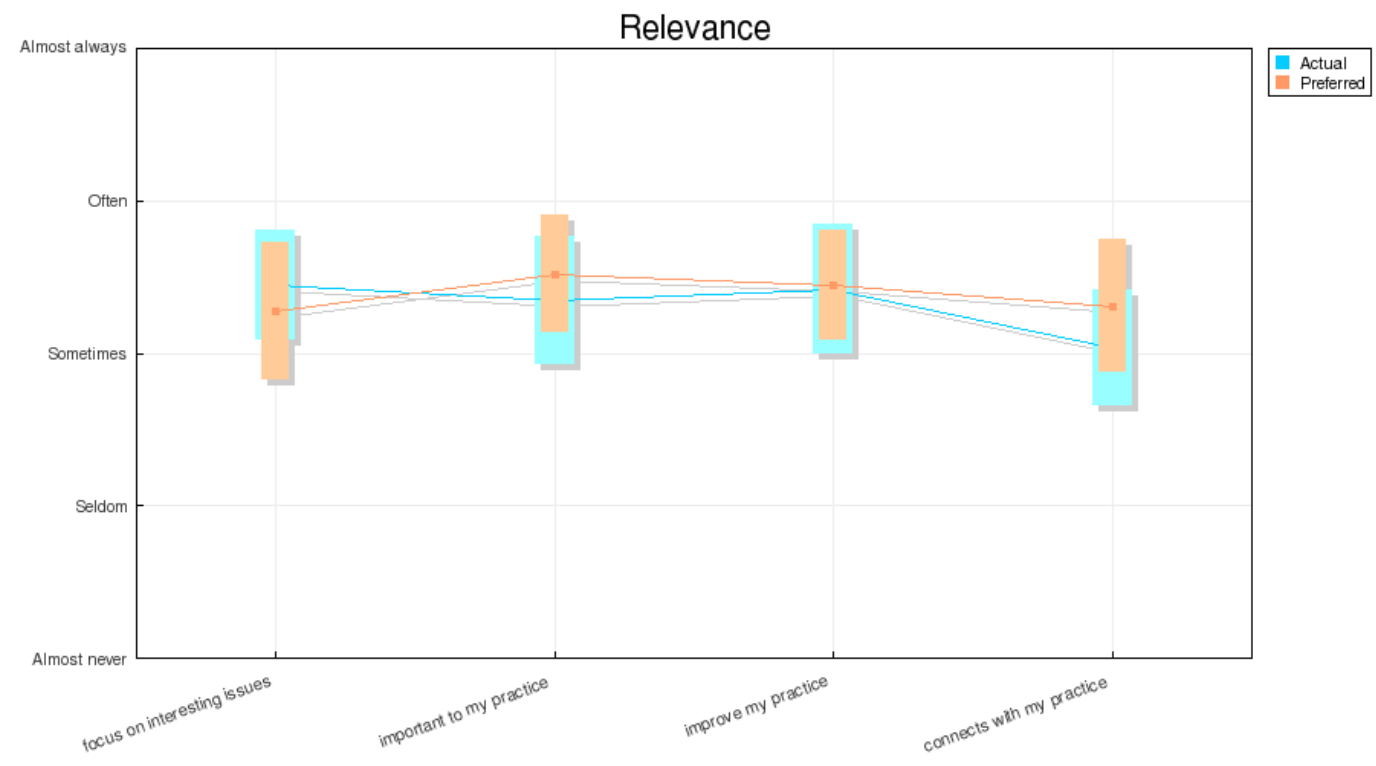

Fig. 1. Relevance of course.

Fig.1 shows preferences and actual student perceptions. The horizontal axis shows item relevance, which are focus on interesting issues, importance of student practice, improvement of student practice, and connection with student practice. Perception averages show that they exceed the "sometime" region, indicating that perceptions are positive. The two items "important to my practice" and "connects with my practice" show greater positive tendencies, indicating that these two areas relate more strongly to interactive activities.

Fig. 2 shown profiles of reflective thinking. The horizontal axes consists of four items: "I'm critical of my learning", "I'm critical of my own ideas", "I'm critical of other students", and "I'm critical of readings". Perception averages show that they exceed the "sometime" region, indicating that perceptions are positive. The largest discrepancy occurred in the item of "I'm critical of my own ideas". This gap relates to SK (separate knowing) on Attitude Toward Thinking Learning Survey (ATTLS). 


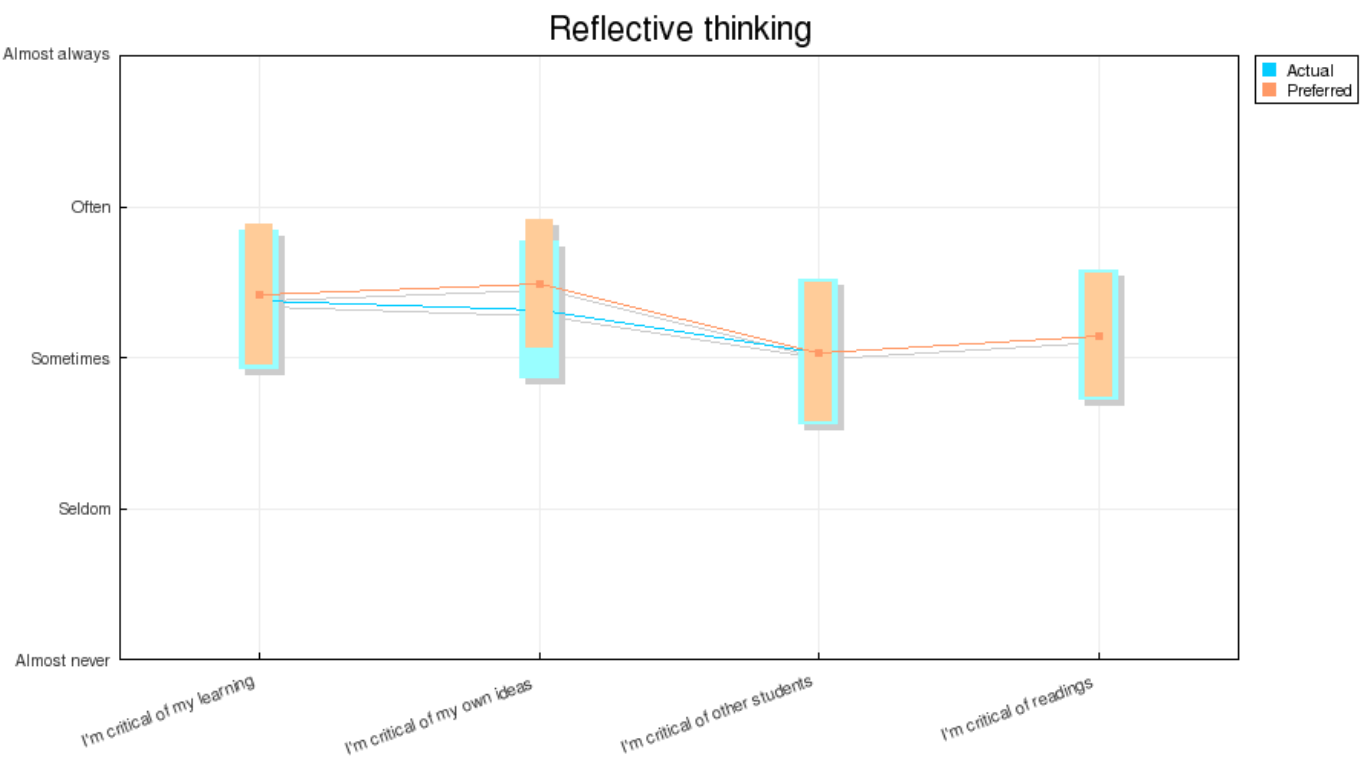

Fig. 2. Reflective thinking.

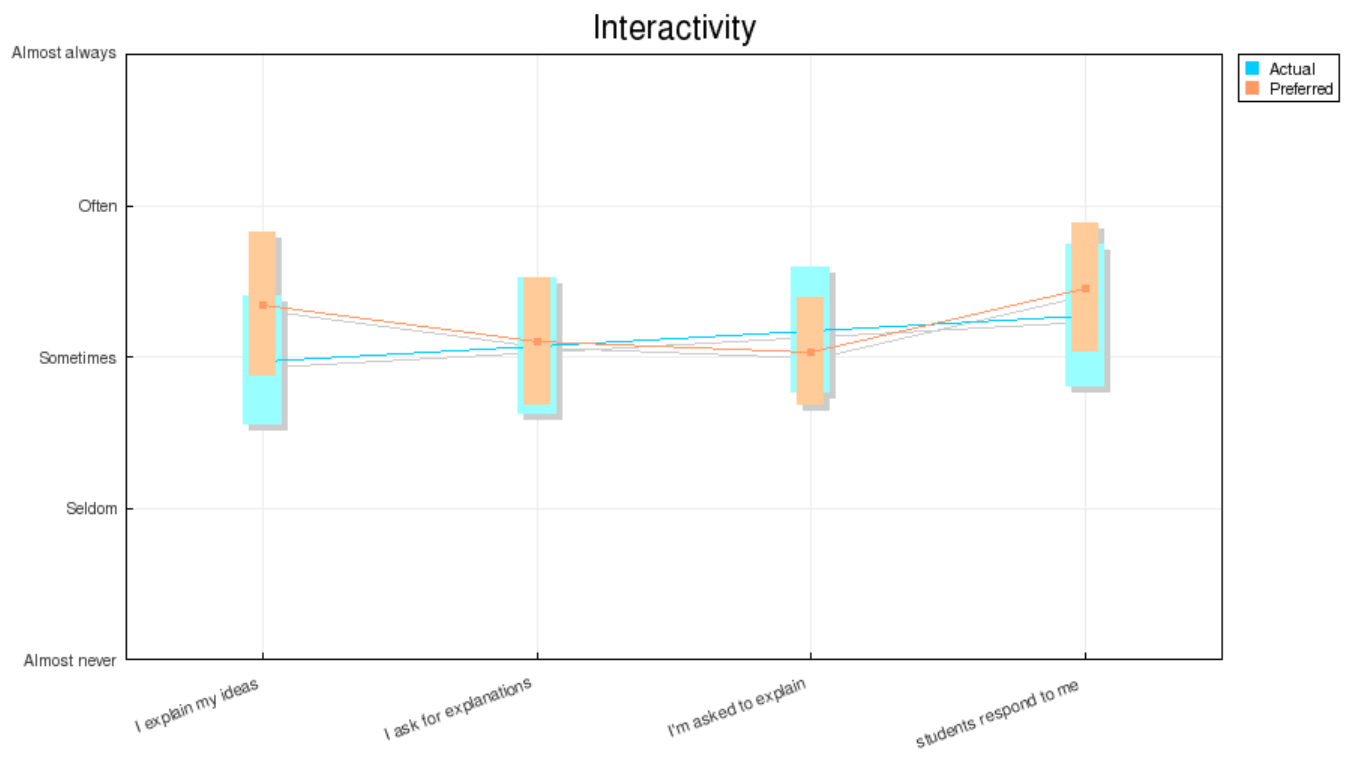

Fig. 3. Course interactivity.

Fig. 3 describes student group activities. The horizontal axis consists of "I explain my ideas", "I ask for explanations", "I'm asked to explain", and "Students respond to me". The profiles shown are not in the seldom and almost-never area, indicating that perceptions are positive. The largest discrepancy occurred in the item of "I'm explain my idea". The gap means the lack of explanation his/her ideas to other students. Fig. 3 profiling interactivity are above the seldom and almost-never areas; in other words, the interactivity is positive.

Fig. 4 introduces tutor a supporting profile. The average line exceeds the seldom and almost-never area, meaning tutor support profiles are positive. The largest discrepancy occurred in the item of "tutor encourages me" profile, indicating students prefer that tutors encourage them to participate more. The gap has been influenced by lack of interaction.

Fig. 5 shown the average of peer support profile are spread in the middle area. The largest discrepancy occurred in the item of e-learning course "Students value me" bar. The gaps means other students value our 
contribution over theirs. The gaps show lack of interaction. The highest actual condition is "students empathize", shown on the right green bar. On one hand, students empathize with our work; however, their value of our contributions is not satisfactory.

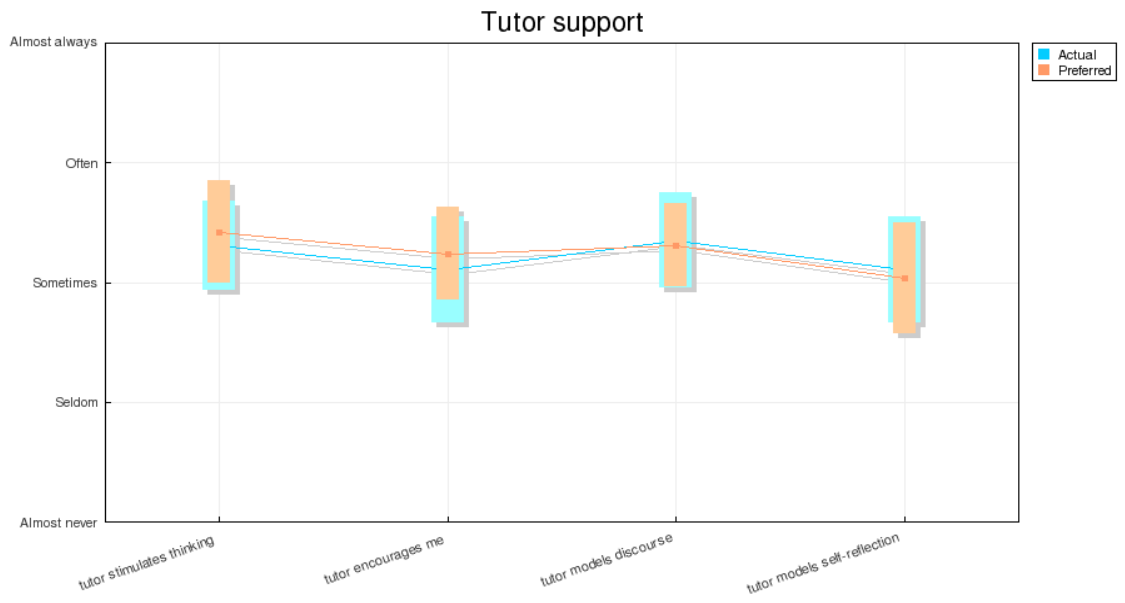

Fig. 4. Tutor support in the e-learning course.

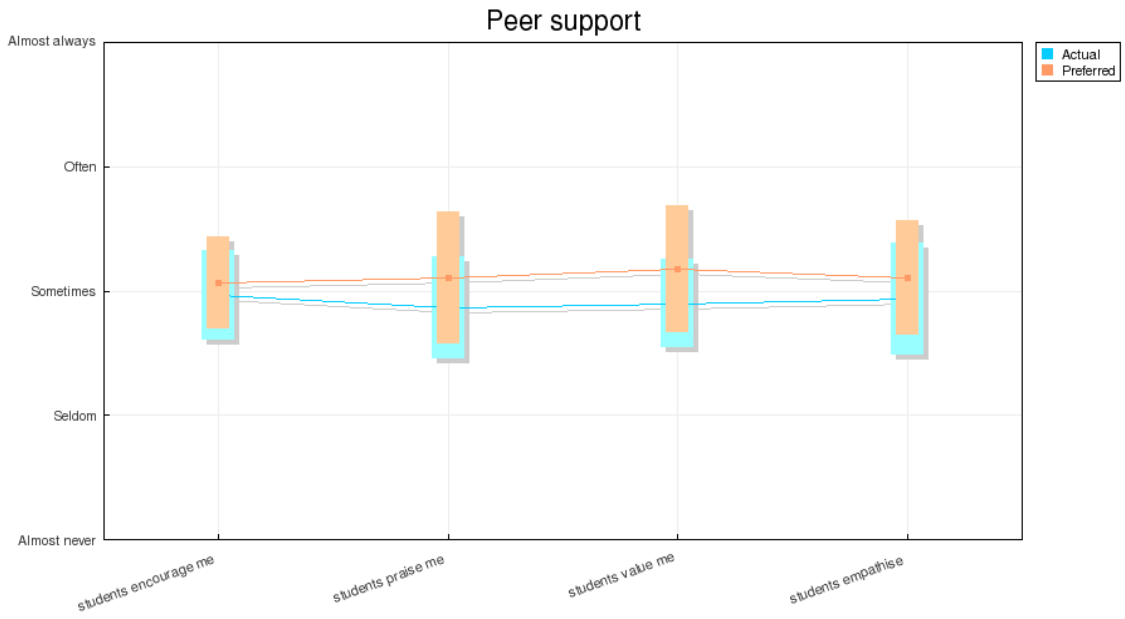

Fig. 5. E-learning course peer support.

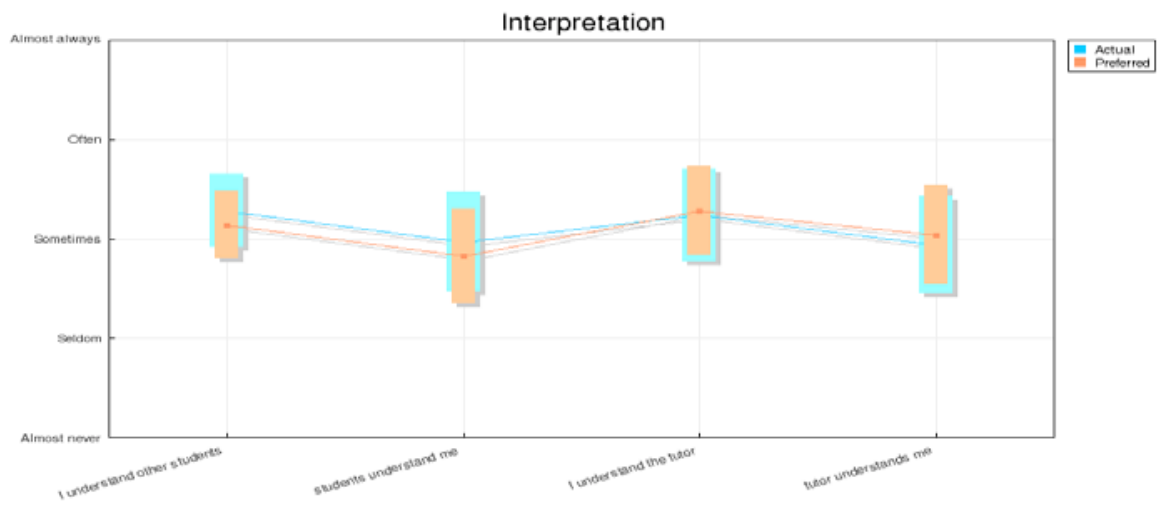

Fig. 6. Interpretation students' profile.

Fig.6 introduce of the students' interpretation. The average line are on the middle are, on the sometimes area. The interpretation profile are still positive. The big positive gap is "I understand other students" 
profile. The gap occurred as the number of actual condition was higher than preferred condition. This gap means students found that they made good sense of other students' messages. In spite of this, the item "tutor understands me" shows a gap between preferred and actual conditions. This gap means students would prefer that tutors make better sense of students' messages. Both of the gaps are related to interactivity.

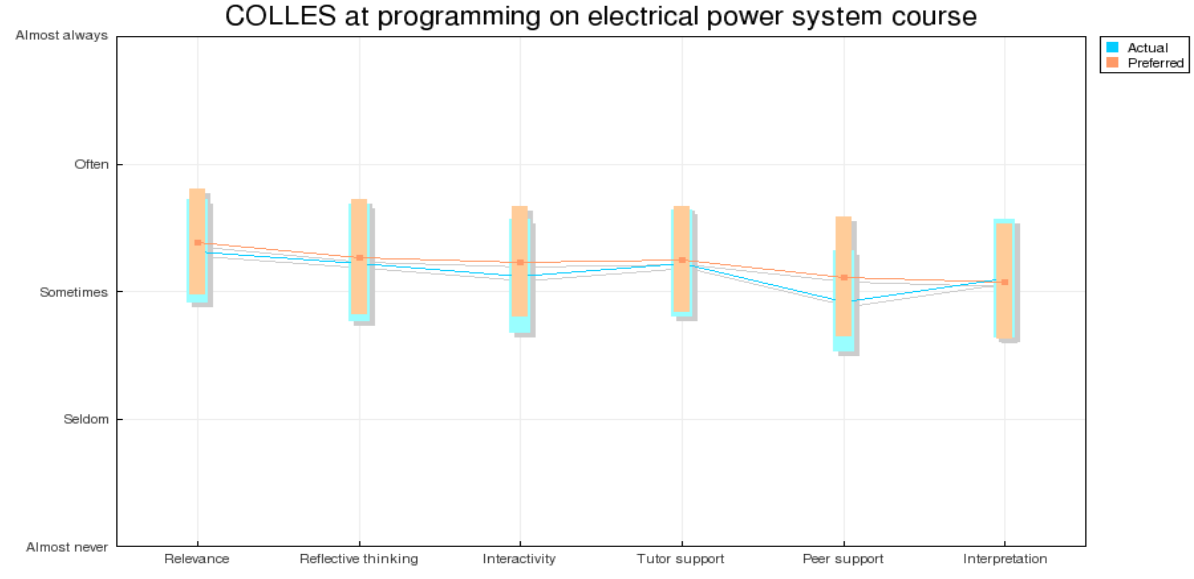

Fig. 7. Conclusion of COLLES.

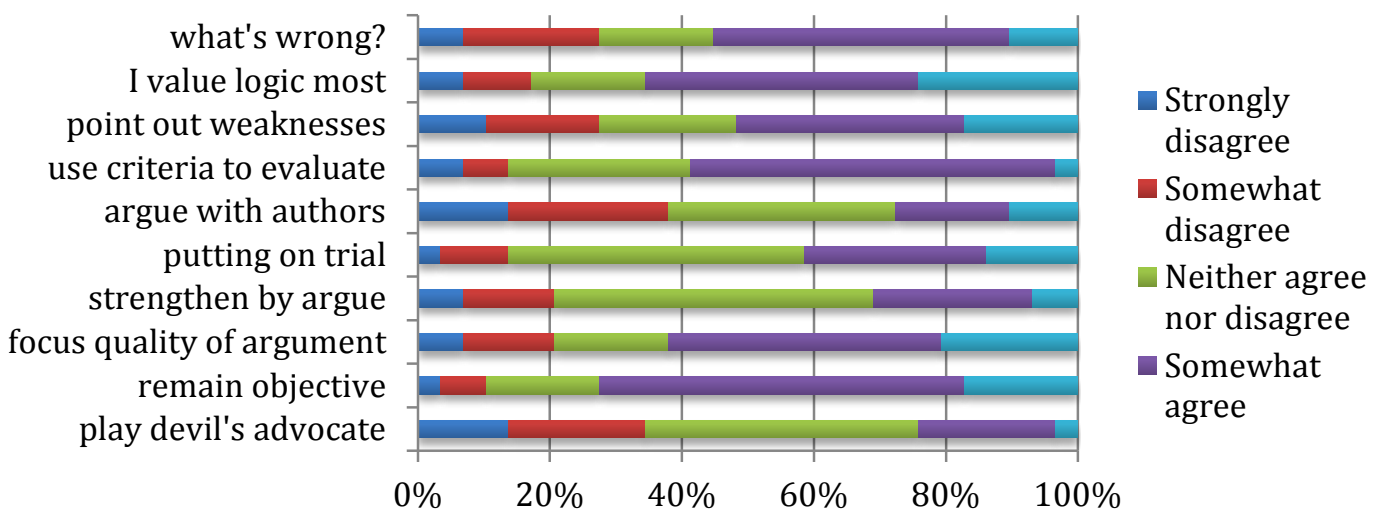

Fig. 8. Separate learning of ATTLS.

Fig. 7 portray conclusion of COLLES on the programming on electrical power system course. The horizontal axes represented COLLES items: relevance, reflective thinking, interactivity, tutor support, peer support and interpretation. The brown bar represents preferred condition, and the light blue bar represents actual conditions. As profiles are not in the seldom and almost-never area, they indicate perceptions are positive. One notable gap from Fig. 7 is that of peer-support; this is an important indication that peer group interaction can influence e-learning achievement. How students can be encouraged, praised, valued, and empathized with by their peers for their contributions or how struggling students and those with low participation can be helped are strategic points toward adaptive e-learning.

Bars in the relevance section show higher level than others. This profile indicates what students learn when they focus on issues that interest them, what is important when they study their professional practice, what they can learn to improve their professional practice, and how what they learn connects with their professional practice. The reflective thinking section indicates whether students think critically about how they learnt, about their own ideas, about other students' ideas, and about ideas in their reading. The interactivity section in Fig.7 shows that students prefer explaining ideas and interaction which exceeds 
simple personal interaction. The tutor support section shows that tutoring stimulates students' thinking, encourages student participation, and models both good discourse and critical self-reflection. The interpretation section shows both how students interpret other students' messages and the responses they receive and shows that students make good use of their tutor's messages also interpret responses well.

Relevance, reflective thinking and interpretation may classified as knowing-ability, related to separate-knowing (SK) of ATTLS and the intrinsic cognitive load theory. Tutor support, peer support and interactivity are related with connected-knowing (CK) of ATTLS and the extraneous-germane cognitive load theory. The relation of COLLES and ATTLS can be shown by the following figures.

Fig. 8 shows separate-knowing (SK) profiles. Vertical axis items display responses to ten value points. Agreement levels regarding each point, ranging from "strongly disagree" to "strongly agree," are respectively represented by blue, orange, green, purple and light blue color bars, with the horizontal axis showing percentages. The three positive longest bars are "remain objective" (indicating the importance of remaining as objective as possible when analyzing); "focus quality of argument" (indicating focus on argument content rather than the person presenting it); and "I value logic most" (indicating value of logic and reason usage over incorporation of personal concerns when solving problems).

The longest positive agreement three bars in Fig. 8 connect to the highest bars in Fig.7. The connection reflects relevance and reflective thinking and points to knowing of personal memory ability; this represents the intrinsic cognitive load theory.

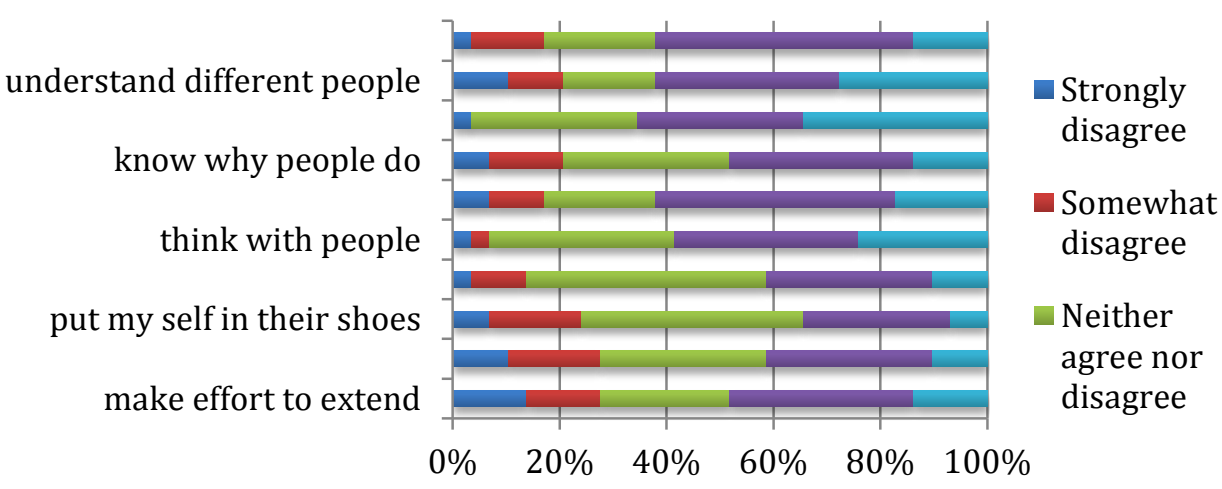

Fig. 9. Connected knowing of ATTLS.

Fig. 9 introduced connected knowing (CK) profiles. Vertical axis items display responses to ten value points. Agreement levels regarding each point, ranging from "strongly disagree" to "strongly agree," are respectively represented by blue, orange, green, purple and light blue color bars, with the horizontal axis showing percentages. Four bars displayed in Fig.9 indicating agreement show percentages exceeding 60\%; they are "enjoy hearing opinions" (indicating enjoyment at exposure to opinions of people who come from different backgrounds to help understand how situations can be seen in such different ways); "interact with variety" (indicating the sense that interaction with a variety of people is optimal to achieve goals); "understand different people" (indicating the sense that the most important part of education is learning to understand disparate types of people); and "where people come" (indicating a desire to understand where other people are 'coming from' - i.e., what experiences have led them to feel the way they do).

Four of the bars represent group activities or those requiring others' resources: those related with interactivity. Fig. 7 and 9 are connected in the items of tutor and peer support. Group activities reflect the extraneous and germane cognitive load theory.

Fig. 10 shows separated-knowing and connected-knowing profiles. The profiles portray levels of agreement. CK has agreement higher than SK, meaning students prefer using a group approach to a 
personal approach. The effectiveness a complex e-learning course may be more helpful for students as they work in groups rather than individually. The effectiveness of the group approach is also reflected by the following figures as comparison.

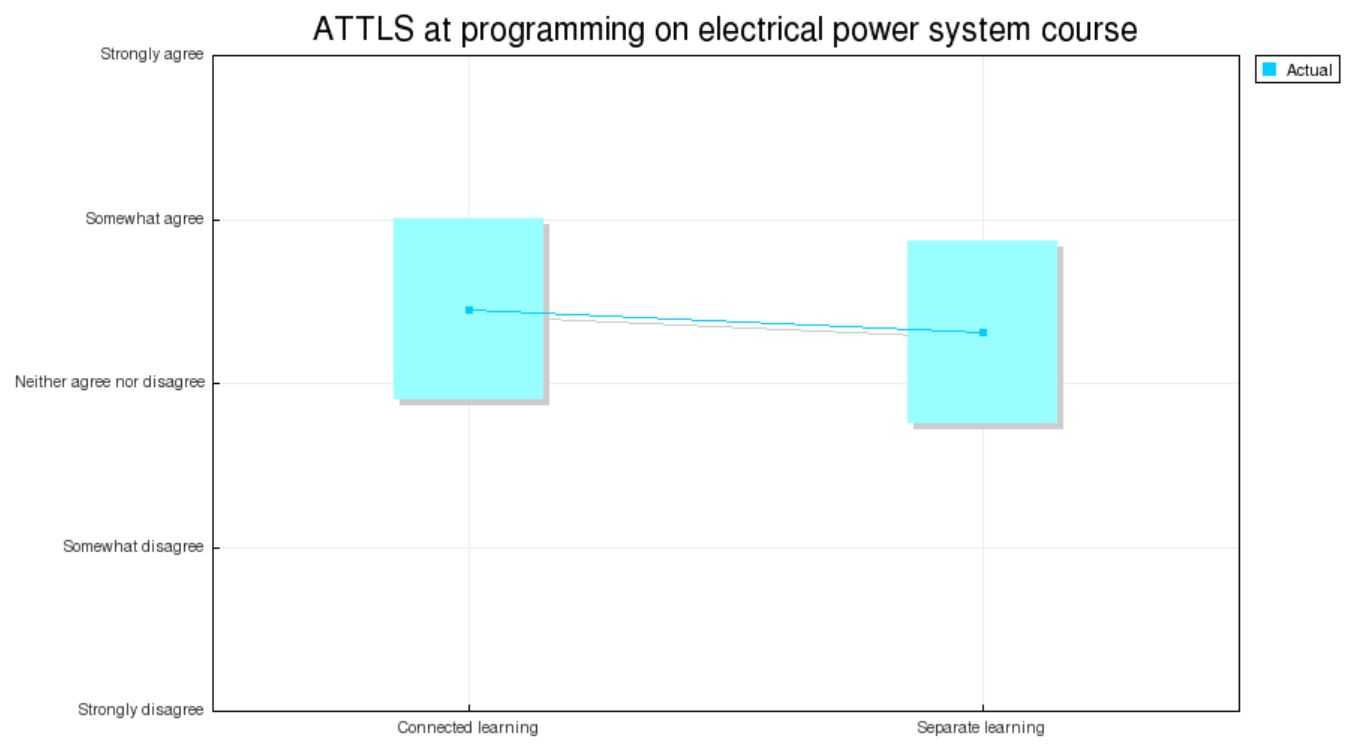

Fig. 10. Conclusion of ATTLS.

\subsection{COLLES and ATTLS at Numeric Method Experiment Course, on First Semester 2016}

Thirty students submitted the COLLES questioners, and 32 students submitted the ATTLS questioners. The course was complex course, and the complexity of the delivery method was identical with the environment of the previous class, programming electrical power systems, in 2016. Students used the same programming tool, VPL [20]. The content consisted of numerical method and programming. From the beginning, students worked in groups. All content material and student activities were accessible via the Unsrat e-learning portal.

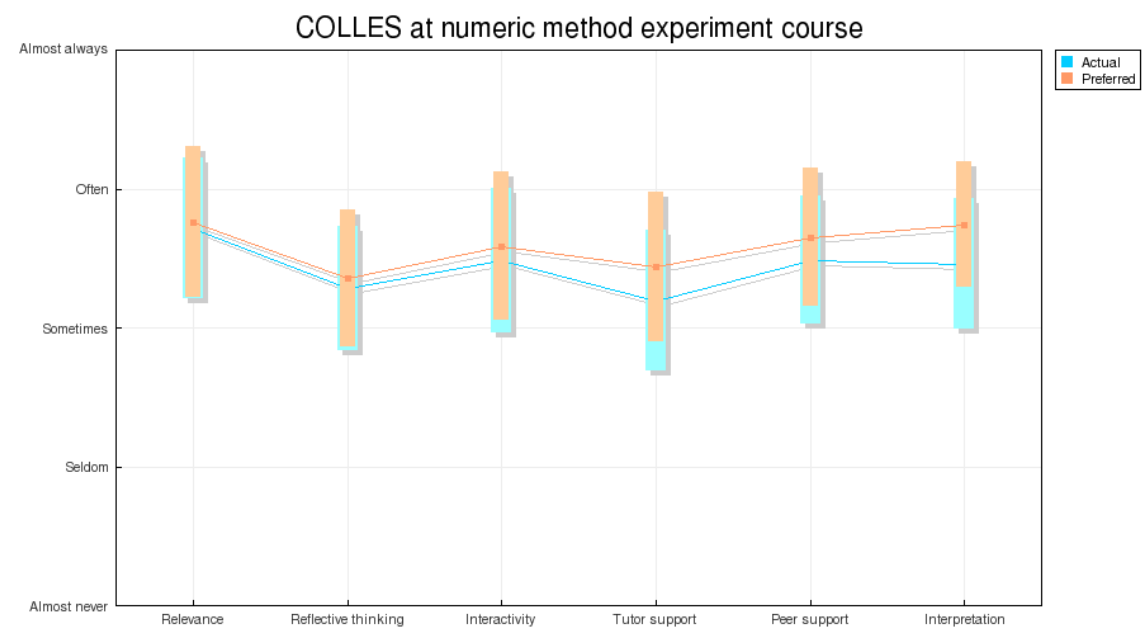

Fig. 11. Conclusion of COLLES at numeric method experiment course.

Fig. 11 portrays COLLES, showing positive perceptions. No profile positions are in the "seldom" or "almost never" areas. "Relevance" shows no significant gap between preferred and actual conditions. The 
two gaps seen are tutor support and interpretation, likely due to the lack of interactivity and indicating the sense of message between students and tutors was not well-facilitated. Students prefer stimulation of thinking and encouragement of participation modeled good discourse and critical self-reflection.

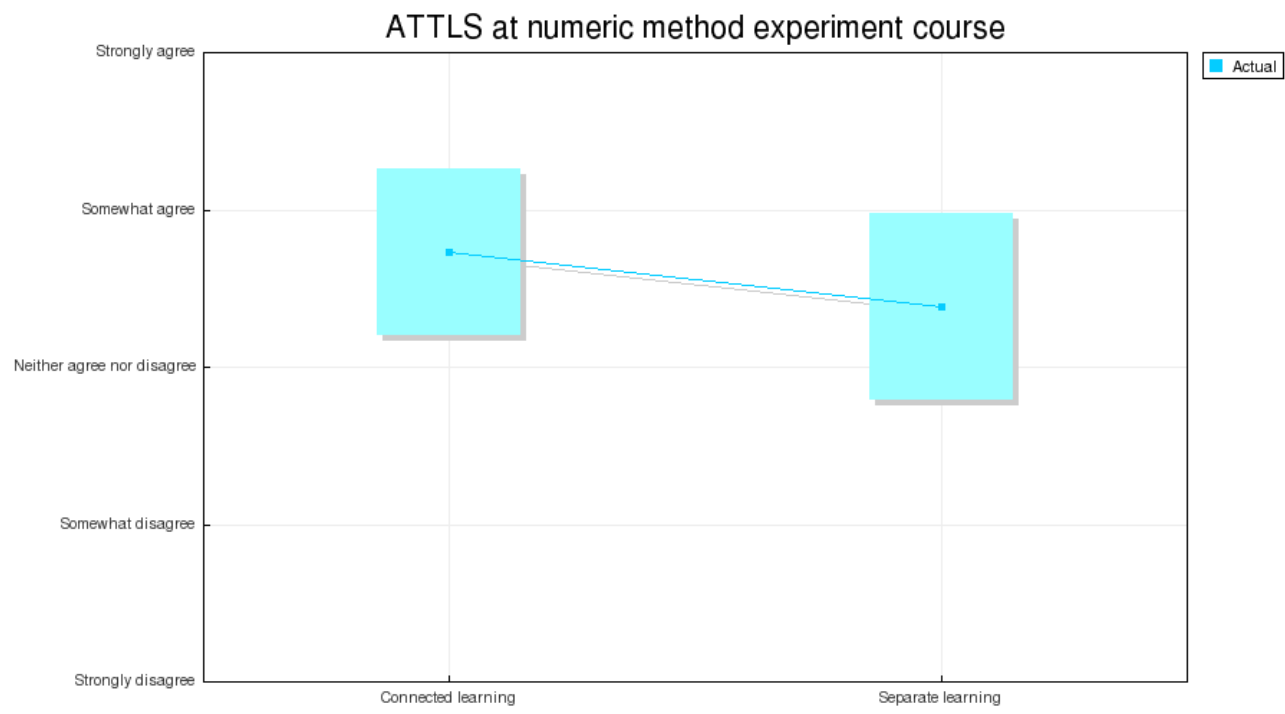

Fig. 12. Conclusion of ATTLS at numeric method experiment course.

Fig. 12 portrays ATTLS profiles. Connected-Knowing (CK) has a level of agreement higher than Separate-Knowing (SK). Both CK and SK are positive. The leveling indicates CK's approach can help students to enhance their understanding and performance. Further, proper combination of CK and SK may help students achieve their course goals.

A comparison of Fig. 11 and 12 with Fig. 7 and 10 show that, of the two complex e-learning courses, the agreement level of CK higher than SK. Interactivity remains a main concern of CK.

\subsection{Off-line Survey}

As comparison, an off-line survey was distributed in 2015 [13] and 2016 [14] regarding programming on an electrical power system course. One question related to the delivery method was "which is preferable to students, theory delivered prior to experiments, or experiments delivered prior to theory." The following table shows students' perceptions.

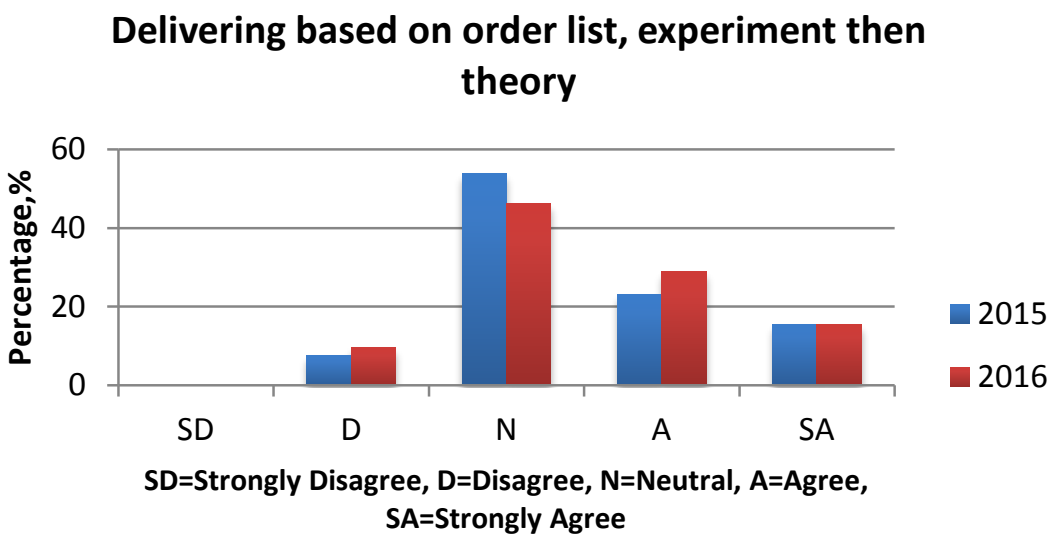

Fig. 13. Students' perception of delivery method. 
Fig. 13 introduces a positive perception of agreement showing that students prefer experiments over theory, with the percentage agreeing outnumbering those disagreeing. The courses' experiments indicated group activities, in which students had more interaction than individual work. By doing experiments in groups, variability of problems encourages students to construct cognitive schemas, and these cognitive schemas subsequently increase the probability that similar features can be identified and that relevant features can be distinguished from irrelevant ones. As such, Fig. 13 is related to Fig. 10 and 12, showing that high variability requires thoughtful engagement of students as learners and increases cognitive load. Problem-solving ability is yielded by better schema construction and transfer of learning. The ability to solve problems is a one function of human memory.

\section{Conclusion Discussion}

Section 3 portrayed result of experiments. These results can be grouped into two approaches: interactivity and group-based. Both approaches are inseparable; they complement one another. Adaptive e-learning methodology accommodates intrinsic, extraneous, and germane cognitive load as most are represented by interactivity and group based activities.

Fig. 3, 7, and 10 corroborate what Luis Palacios and Chris Evans [10] have suggested. Interactivity in pedagogical feedback, audio feedback, and texting feedback experiments produce significant evidence of their effects. In particular, students' perceptions in 2016 [14] have shown the positivity of relevance, reflective thinking and interactivity. As such, interactivity components must be presented in e-learning complex courses. As noted in reference [10], interactivity components are related by active learning environment, learner control, feedback, multiple media, learner response options, and adaptability.

Fig. 4 and 5 indicate that tutor and peer support of students' perceptions relates by level of agreement of Connected-Knowing (CK), as shown in Fig. 9, 10, and 12. The CK profile reflects interactions among factors: students (student-student interaction), tutors (teacher-student interaction), and the teaching material itself (student-content interaction) were shown to be higher than SK. Although the level of agreement of CK was higher than SK, personal cognitive ability as represented by SK must be accommodated properly. Moreover, combining CK and SK styles will serve as a guideline for instructional designers to maximize students' achievement by using types of interactivity related to the delivery method of a complex e-learning courses.

Both Palacios et al. [10] and van Meirrenboer et al. [12] in their results connected with our hypothesis that - that enhancing extraneous cognitive load is superior to the intrinsic cognitive load approach. Most of the extraneous cognitive load can be represented by interactivity. Therefore, a primary list of factors influencing delivery method a complex e-learning course in Indonesia should be interactivity and connected-knowing approaching.

As future work, we hope to measure how interactivity influences behavior, focusing our interest on collaborative thinking of e-learning. As well, how to know the implication of specific way toward e-learning method base on gender or type of content.

\section{Acknowledgment}

Part of this work was supported by Grant-in-Aid for scientific research 25280124 and 15H02795, Kumamoto University, Japan. A scholarship covered by Ministry of Research, Technology and Higher Education of the Republic Indonesia.

\section{References}

[1] Limongelli C, S. C., \& Vaste G. (2011). Personalized e-learning in moodle. The Moodle_LS System. e-Learning and Knowledge Society, vol. 7, no. 1, 49-58. 
[2] Wright, J. Edtech digest. (2016, September). Retrieved from the website: https://edtechdigest.wordpress.com/2016/09/20/getting-personal/

[3] Matteo Gaeta, S. M., Francesco Orciuoli, S. P., \& Antonell, P. (2013). An approach to personalized e-learning. Systemics. Cybernetics and Informatics, 11(1), 15-21.

[4] Inma, R-A., \& Antoni M-A. (2016). E-learning continuance: The impact of interactivity and the mediating role of imagery, presence and flow. Information \& Management, 504-516.

[5] Erman Y., \& Zahide Y. (2008). Investigation of interaction, online support, course structure, and flexibility as the contributing factors to students' satisfaction in an online certificate program. Educational Technology \& Society, 11(4), 51-65.

[6] Steffi, D., Ruth N, S., \& Jan L P. (2010). Interactivity in multimedia learning: An integrated model. Computers in Human Behavior, 26, 1024-1033.

[7] Edmundo, T., \& Nelson, P. (2014, November). Guest editorial: Open educational resources in engineering education: Various perspectives opening the education of engineers. IEEE Transaction on Education, 57(4), 213-219.

[8] Andreea, I. (2012). New e-learning method using databases. Database Systems Journal, 3(3). 35-46.

[9] Kusuma A. L., \& Zainal A. H. (2015). Personalized e-learning architecture in standard-based education. 2015 International Conference on Science in Information Technology (ICSITech), 110-114.

[10] Luis, P., \& Chris, E. (2013). The Effect of Interactivity in e-Learning Systems. Newcastle, UK: Cambridge Scholars Publishing.

[11] Heath, M., \& Stephen L B. (2009, January). Relationships between separate and connected knowing and approches to learning. Journal of Research Sex Roles, 60, (1), 57-66.

[12] van Merrienboer J.J.G., \& Ayres P. (2005). Research on cognitive load theory and its design implications for e-learning. Educational Technology Research \& Development - ETR\&D, 53(3), 5-13.

[13] Sumenge, G. K., Sary, P., Glanny, M., Yoshifumi C., \& Tsuyoshi, U. (2016). Design and implementation of programming on electrical power system as an e-learning subject course at University of Sam Ratulangi Indonesia. e-Learning and ICT Cooperative Use by University, 115 (492), Kagawa-Japan, 33-37.

[14] Sumenge T. G. K. et al. (2016). Student perceptions of virtual programming lab on e-learning class at University of Sam Ratulangi. 2016 International Conference on Information, Communication Technology and System (ICTS), Surabaya, 244-248.

[15] Martin, D., \& Peter, C. T. (2002). Interpretative analysis of an internet-based course constructed using a new courseware tool called Moodle. Retrieved from the website: https://dougiamas.com/archives/herdsa2002/

[16] Taylor, P., \& Maor, D. (2000). Assessing the efficacy of online teaching with the Constructive On-Line Learning Environment Survey. Proceedings of the 9th Annual Teaching Learning Forum, Perth.

[17] Kathleen, M. G., Blythe, M. C., Kathryn, H. A., Beth, L., \& Annick, F. M. (1999, May). A new way of assessing ways of knowing. The Attitudes Toward Thinking and Learning Survey (ATTLS). Sex Roles, 40(9), 745-766.

[18] Clare, P., \& Kiyomi D. (2010). Peer facilitated learning in mathematics for engineering: A case study from an Australian university. Engineering Education, 5(1), 75-84.

[19] Atkinson, R.C., \& Shiffrin, R.M. (1968). Human memory: A proposed system and its control processes. Journal Psychology of Learning and Motivation, 2, 89-195.

[20] Dominique, T. (2015). Automatic evaluation of computer program using Moodle's virtual programming lab (VPL) plug-in. Journal of Computing Science in College, 30(6), 146-151.

[21] Moodle.org. Survey module. Retrieved from the website: https://docs.moodle.org/22/en/Survey_module/ 
Sumenge Tangkawarouw Godion Kaunang graduated from electrical department of ITS Surabaya and master electrical engineering at ITB Bandung Indonesia. He joined University of Sam Ratulangi in 1993. Since 2014, he has been a doctoral student of Kumamoto University, Japan. His interests are e-learning content and systems and electrical power system computation.

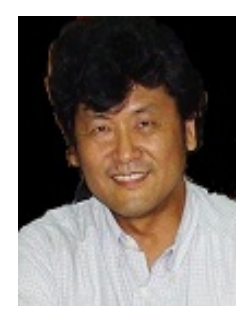

Tsuyoshi Usagawa joined Kumamoto University in 1983 after receiving his M.E. degree from Tohoku University. In 1988, he received Dr. Eng. from Tohoku University. A professor since 2004, he is a member of IEEE, ASA, ASJ, and INCE/J. He is interested in e-learning content and systems and acoustic signal processing. 